\title{
Simulating musical rotation, contour and notes: the perception of (e)motion in nonmusicians
}

\author{
Anna Kolesnikov ${ }^{1}$, Joshua Bamford ${ }^{2,3}$, Eduardo Andrade ${ }^{4}$, Martina Montalti ${ }^{5}$, Marta \\ Calbi $^{5}$, Nunzio Langiulli ${ }^{5}$, Manisha Parmar ${ }^{6}$, Michele Guerra ${ }^{1}$, Vittorio Gallese ${ }^{5,7}$, \\ Maria Alessandra Umiltà ${ }^{6,7}$
}

${ }^{1}$ Department of Humanities, Social Sciences, and Cultural Industries, University of Parma, Parma, Italy

${ }^{2}$ Social Body Lab, Institute of Cognitive and Evolutionary Anthropology, School of Anthropology \& Museum Ethnography, University of Oxford, Oxford, United Kingdom

${ }^{3}$ School of Psychological Science, The University of Western Australia, Perth, Australia

${ }^{4}$ Royal College of Music, London, United Kingdom

${ }^{5}$ Department of Medicine and Surgery, Unit of Neuroscience, University of Parma, Parma, Italy

${ }^{6}$ Department of Food and Drug, University of Parma, Parma, Italy

${ }^{7}$ Department of Art History and Archeology, Columbia University, New York, USA

Version: $28-06-2021$

*Correspondence:

Anna Kolesnikov

anna.kolesnikov@unipr.it

Keywords: embodied music cognition, musical mimesis, musical motion, musical rotation, nonmusicians 


\section{Introduction}

The perceived "motion" of music has been of interest to philosophers and musicologists since the time of Aristotle in his Problemata, and although traditional cognitivist approaches consider music a purely auditory event, it is actually one of the most embodied experiences that belong to the repertoire of human activity. Stemming from a rich tradition of scholarly work on melodic motion (such as: Schenker (1906/1954), Hanslick (1891), Pratt (1931/1958), and Truslit (1938)), Zuckerkandl asserted in Sound and Symbol (1956) that, "Whatever else music may be, one thing it must be: motion" (Zuckerkandl, 1956: 81). As Godøy and Leman note (2010), music is fundamentally "a combination of sound and movement", and the meaning of music for humans derives from this very combination, or what they term "musical gestures". Indeed, the kinetic qualities of music are made evident in embodied metaphors such as crescendo, decrescendo, accents, attack, staccato, legato, accelerando, and ritardando, all modes of movement which are so deeply encoded in our language that "it is almost impossible not to think of music in those terms" (Stern, 2010: 57). According to the framework of embodied music cognition, part of how we comprehend music is by imitating either overtly or covertly the observed sound-producing actions of performers, also known as mimetic motor imagery (Cox, 2017). The present study investigates the relationship between formal acoustic features, perceived motion (in horizontal and vertical planes) and involvement measures in nonmusicians, specifically testing the Ecological Theory of Rotating Sounds (Hansen and Huron, 2019) and the mimetic subvocalization hypothesis (Cox, 2017) using a novel, naturalistic set of stimuli.

\section{Music and sensorimotor engagement}

The advent of neuroimaging techniques has made it possible to investigate the role of sensorimotor engagement in musical experience. Zatorre et al. (1996) demonstrate that perceiving a melody and imagining a melody involve overlapping neural systems, and activation of the supplementary motor area (SMA) occurs in both tasks, pointing to a combination of re-hearing and re-enacting, or re-singing. Similarly, Hickok et al. (2003) found activation of shared auditory and motor brain areas in both perception and voluntary covert rehearsal of music. Consistent with the previous two studies, Callan et al. (2006) found activation in the SMA as well as brain sensorimotor areas known to map the lips and tongue. In order to exclude the possibility of linguistic processes, Halpern and Zatorre (1999) 
investigated auditory imagery for familiar melodies without lyrics, with PET scans demonstrating activation of SMA in imagery for the continuation of familiar melodies as well as in reimagining novel melodies, with the authors speculating that the SMA is involved in motor processes related to the formation of auditory imagery regardless of familiarity.

Studies have also demonstrated the existence of instrument-specific and rhythmic mimetic motor imagery. Halpern et al. (2004) found that the SMA was activated during similarity judgements involving different kinds of musical instruments, indicating a potential non-vocal motor imagery related to how the different instruments (e.g., a flute or trumpet) could be played. Baumann and colleagues (2007) reported that during audio-motor coordination a network of predominantly secondary and higher order auditory and motor areas were activated in both musicians and nonmusicians, with the dorso-lateral premotor cortex (dlPMC) and the pre-supplementary motor cortex (preSMA) activation significantly increased for pianists. In two fMRI experiments, Chen, Penhune and Zatorre (2008a) found that the same motor areas were activated in participants who were instructed to tap along after listening as well as in participants that were instructed to listen only. Mid-premotor cortex (mid-PMC) was significantly engaged not only during listening with anticipation and movement synchronization but also during naive passive perception when there was no sound-movement association. The dPMC was activated when subjects synchronized their movements, and the vPMC was activated when subjects listened with anticipation and synchronized their movements. The finding that brain areas thought to be involved in polymodal motion processing are activated during music perception corroborate a ventral-dorsal premotor dissociation (Chen, Penhune and Zatorre, 2008b). Chen and colleagues posit that mid-PMC engagement may be a result of long-learned sound-movement associations, priming the brain for action.

In their theory of the co-representation of musical experience (i.e., the Shared Affective Motion Experience model [SAME]), Avery and Molnar-Szakacs (2006/2009) posit that musical meaning is conveyed through implied movement, which may be pivotal for musical empathy. Going further, the authors also propose that the existence of a common neural substrate for music, language and motor functions is supported by evidence from studies of language disorders, in which children with dyslexia have been found to exhibit difficulties in musical timing (Overy et al., 2003), motor control (Wolff, 2002) and language (Goswami, 2015), as well as evidence of music lessons and speech therapy based on singing benefiting patients with 
severe non-fluent aphasia (Sparks et al., 1974). Though the tendency to move in rhythmic synchrony with a musical beat is universal in humans, it was thought until very recently that this faculty did not extend to non-human animals. Indeed, recent findings (e.g., Patel et al., 2009; Rouse et al., 2016) provide clear evidence for a shared faculty in beat keeping across multiple species, suggesting that the human ability to synchronize to musical rhythm stems from a broadly conserved, deeply rooted neurobiological mechanism.

\section{Embodied music cognition and the human voice}

Drawing from the mimetic hypothesis (Cox 2001/2011/2017), Cox posits that musical meaning begins with the imitation of musical sounds and of the physical exertions that they produce. A particular kind of auditory-motor imagery is related to planned, recalled or imagined speech actions, known as subvocalization, or inner speech (Cox, 2017: 28). Subvocalization is a covert type of vocalization, such as the sound and feel of one's voice when reading, and mimetic subvocalization is a particular kind of subvocalization in which another's spoken words or singing is covertly imitated. A form of mimetic motor imagery, Cox extends mimetic subvocalization to the imitation of musical sounds more generally (i.e., musical instruments). For most people, the voice is the first and most common means of auditory communication and understanding the vocal expressions of others. Capable of imitating virtually all sounds without special training, the voice is deeply embodied and is not limited to the larynx (Cox, 2017: 31). Specifically, "head" and "chest" voice refer to the sensation that the internal resonance of the voice seems to migrate from the chest to the head when one sings from low to high pitch. Change of pitch in vocalization occurs through the tightening or relaxing of the vocal cords via the laryngeal muscles in coordination with muscles such as the diaphragm which force air through the vocal folds (Cox, 2017: 90). This may be the origin of the association of pitch height to motion in vertical space, and Cox refers to this phenomenon as the "human voice as source domain" hypothesis. As Roger Sessions observes in The Composer and His Message (Sessions, 1941: 108), from childhood we learn that if we raise our voice, we often end up raising pitch height - they go hand in hand. "Higher" pitch corresponds to greater tightening or muscular tension, a feeling of greater effort, and thus a heightened affective state, i.e., the "greater [exertion] is higher" metaphor. Indeed, all singing involves activation of the abdominal muscles, shaping musical experience by way of correlations between abdominal exertions (tightness and relaxation) and emotional states. Pitch contours are often described vertically in many languages, with "high" pitch usually referring to a greater frequency, 
although this is not universal (Žuvela and Anić, 2019). Previous research has attempted to find an association between verticality metaphors for pitch perception and bodily expression, although without finding significant results (Kelkar and Jensenius, 2019).

\section{The Ecological Theory of Rotating Sounds}

While some cross-modal associations are innate, others may arise from learned, common environmental occurrences. Gibson (1966/1979) argues that an analysis of the environment is crucial to explaining behavior. Applying the Gibsonian perspective to the study of music, ecological acoustics studies the relationship between human beings and their environment as mediated through sound, positing that listeners acquire practical knowledge from sounds in their acoustical surroundings rather than abstract concepts such as frequency, duration, and intensity. Hansen and Huron (2019) suggest that one such phenomenon is the perception of triplet rhythms. Although music scholars have long been aware of the sensation of rotation evoked in listeners, Hansen and Huron observe that no theory has been proposed to account for this "apparent association". Drawing from the domain of ecological acoustics, the authors propose an Ecological Theory of Rotating Sounds (EToRS), which maps fluctuations in loudness (i.e., accents) to trajectories of rotating sound sources. According to the theory, in the absence of an existing metrical context, the listener tends to hear the loudest event as marking the downbeat (Hansen and Huron 2019). Thus, if the listener is situated outside the trajectory of the rotating sound, binary patterns (two beats per measure) reduce to pendular motion, whereas ternary note patterns (three beats per measure) reduce to spinning movement, and for quaternary (four beats per measure) and quinary note patterns (five beats per measure) it is ambiguous as to whether the motion is reduced to spinning or pendular motion. Testing their theory in a mixed population of professionals, semi-professionals and amateur musicians, the authors report that: 1) ternary note patterns were perceived as more spinning/rotating than nonternary patterns, but that the difference is driven primarily by low rotating ratings for binary patterns, and 2) when pitch contour is moving, loudness patterns consistent with rotating trajectories are perceived as more rotating than unecological patterns, providing moderate support for an ecological account of rotating sounds. 


\section{Research aims}

As described in the aforementioned literature, there are numerous studies on the cross-modal interactions of music in terms of association with physical space and bodily motion. Furthermore, there is considerable evidence and a strong conceptual framework for the claim that an integral part of how we understand human movement and human-made sounds is in terms of our own experience of imitating the source of visual and auditory information, grounded in our own body's ability to make similar sounds. Thus, the aims of the current study are to investigate the impact of multiple formal musical features on the perception of motion in a population of nonmusicians. Specifically, the impact of Composition Contour (Ascending, Descending, Flat), Composition Complexity (i.e., number of melodic voices) (Low, Medium and High) and Note Pattern (Binary, Ternary and Quaternary) were investigated with respect to perceived Movement, perceived Rotation, Direction, and Emotional and Physical Involvement. In order to attain these aims, we designed a novel, naturalistic set of musical stimuli in collaboration with the film composer Eduardo Andrade. We hypothesize that: 1) participants will correctly identify the Direction of the musical stimuli (i.e., Ascending, Descending or Flat), 2) Ternary Note Pattern will be perceived as evoking more Rotation than Quaternary and Binary; 3) High Composition Complexity will be perceived as evoking more Emotional Involvement, Physical Involvement and Movement with respect to Medium and Low; and 4) Ascending Composition Contour will be perceived as evoking more Emotional Involvement, Physical Involvement and Movement than Descending and Flat.

\section{Materials and methods}

\section{Participants}

Participants were recruited through opportunity sampling using Facebook, which filtered individuals for age, residence in Parma and a nonmusician background. Participants were further screened for musical training prior to participation based on a screening questionnaire, in which individuals with more than 6 years of music classes within the school curriculum or private musical tuition were excluded (including voice), with an average total number of years of musical training of $2 \pm 1.75$ Standard Deviation (SD) years. In total, 30 healthy volunteers of Italian nationality took part in the study: 16 females and 14 males, mean age 28.76 (SD = $4.64, \min =18, \max =35)$. All participants reported having normal hearing and normal or 
corrected-to-normal visual acuity. All participants were either right-handed or ambidextrous (as determined by the Edinburgh Handedness Test; Oldfield, 1971). We calculated the sample size by using G*Power 3.1 (Faul, Erdfelder, Lang, \& Buchner, 2007) and running a priori power analysis equivalent to that of a mixed-design multilevel linear model, with a level of power of 0.80 , assuming a Cohen's F effect size equal to 0.25 (medium effect size), an alpha level of 0.05 , and 5 measurements. All participants provided written informed consent to participate in the study, which was conducted in accordance with the Declaration of Helsinki (2013), complying with the ethical standards of the Italian Board of Psychologists as well as the Ethical Code for Psychological Research of the Italian Psychological Society and the Ethical Committee of the Area Vasta Emilia Nord (AVEN).

\section{Stimuli creation}

In collaboration with a film composer, musical variations of melodic motion were composed. Eduardo Andrade created ten-second digital piano tracks with Digital Audio Workstation (DAW) using Cubase Pro software, with the piano sample from Garritan/Abbey Road CFX Grand. The tracks were created in the following modalities: melodies with Ascending, Descending, or Flat Composition Contour, with Binary, Ternary or Quaternary Note Pattern, and with Low, Medium or High Composition Complexity (see Tab. 1), thus following a $3 * 3 * 3$ design for a total of 27 tracks. The tracks were composed on a digital piano due to the greater ease of gradually integrating Composition Complexity through use of the left and right hands. All notes were played with a certain degree of human variability in their dynamic in order to increase likeness with the dynamics of how human music is usually performed (see Supplementary Materials for stimuli partition). In order to prioritize the investigation of perceived motion, the composer avoided the explicit expression of "valence" through key in his compositions, striving for "neutrality". All tracks were balanced for volume and melodic structure and formatted as Waveform audio files (WAV) with a sampling rate of $44.1 \mathrm{kHz}$ and 16 bits per sample. 


\begin{tabular}{cccc}
\hline Stimulus & Contour & Note Pattern & Complexity \\
\hline $1-9$ & Ascending & Binary & L, M, H \\
& & Ternary & L, M, H \\
& & Quaternary & L, M, H \\
\hline $10-18$ & Descending & Binary & L, M, H \\
& & Ternary & L, M, H \\
& & Quaternary & L, M, H \\
\hline $19-27$ & Flat & Binary & L, M, H \\
& & Ternary & L, M, H \\
& & Quaternary & L, M, H \\
\hline
\end{tabular}

Tab. 1 | Stimuli /conditions. Total number of stimuli: 27. L: Low, M: Medium, H: High.

\section{Procedure}

Upon arrival, participants were asked to make themselves comfortable and were given instructions about the study. The experimental session consisted of two different and randomized phases.

In the first phase, participants were asked to fill out a series of questionnaires. Empathy was assessed in all participants using the Interpersonal Reactivity Index (IRI, Davis, 1980). The IRI consists of 28 self-report items, answered on a 5-point Likert scale ranging from 1 ("Does not describe me well") to 5 ("Describes me very well"). The measure has 4 subscales, each made up of 7 different items that measure empathy as a multidimensional construct. Analysis focused on the Empathic Concern (EC) subscale, which assesses "other-oriented" feelings of sympathy and concern for unfortunate others, and the Fantasy (F) subscale, which taps respondents' tendencies to transpose themselves imaginatively into the feelings and actions of fictitious characters in books, movies, and plays. Motor imagination was assessed in all participants using the VMIQ-2 (Roberts et al., 2008). The VMIQ-2 consists of 36 self-report items that measure the vividness of motor imagination, with three subscales: External Visual Imagination (i.e., imagining yourself carry out the movement as you observe from the outside), Internal Visual Imagination (i.e., imagining yourself carry out the movement through your own eyes), and Kinesthetic Imagination (i.e., imagining the physical sensation of carrying out the movement). Items are answered on a 5-point Likert scale ranging from 1 ("Perfectly clear and vivid, like in normal vision") to 5 ("No image, only awareness of thinking about the movement"). General attitudes to music were assessed in all participants using the BMEQ (Werner, Swope and Heide, 2006). The BMEQ consists of 53 self-report items, covering a wide range of topics pertaining to the place of music in a person's life, both for musicians and nonmusicians. Two subscales were of interest here: affective reactions (A) (affective and spiritual reactions to music; 10 items) and reactive musical behavior (R) (motile reactions 
including humming and swaying, along with music; 9 items), with responses measured on a 5point Likert scale ranging from 1 ("Very untrue") to 5 ("Very true"). Handedness was assessed in all participants using the Edinburgh Inventory (Oldfield, 1971). Containing 19 self-report items, the survey assessed whether participants were right-handed, left-handed or ambidextrous. Left-handed subjects were excluded.

In the second phase, participants were asked to perform a computer task in which the 27 audio tracks were presented in randomized order. In each trial, a fixation cross was presented for $1000 \mathrm{~ms}$, the audio stimulus was presented for $10000 \mathrm{~ms}$ (with a black screen), and afterward a question was presented with no time limit (see Fig. 1). Each stimulus was presented five times, each time followed by one of the following questions, also in randomized order: 1) "What direction was the music moving in?”; 2) "How much movement did you perceive?"; 3) "How much rotation did you perceive?"; 4) "How physically involved did you feel?"; and 5) "How emotionally involved did you feel?". Participants were asked to observe the stimuli and answer the questions as quickly and as accurately as possible (no specific time limit was given), using the mouse to click on the Visual Analogue Scale (VAS) ranging from 0 (very little) to 100 (very much). Only for the "Direction" question, 0 signified "down" and 100 signified "up". The study design was the following: 3 Composition Contours (Ascending, Descending, Flat) * 3 Note Patterns (Binary, Ternary, Quaternary) * 3 Composition Complexities (High, Medium, Low), for a total of 27 conditions. Each experimental condition was repeated five times, for a total of 135 presented trials. Before carrying out the experimental procedure participants were presented with a brief training phase to become accustomed with the task. After the experimental session participants were asked to fill out a short debriefing survey about their experience. The experimental session and was conducted in a quiet room, on a screen positioned approximately $60 \mathrm{~cm}$ from the participant and using Sony WH1000XM2 Noise Cancelling headphones with an intensity at the sound source of $75 \%$ maximum volume (see Fig. 1). The experimental task was programmed using Psychopy 3.0 software (Peirce, 2019). 


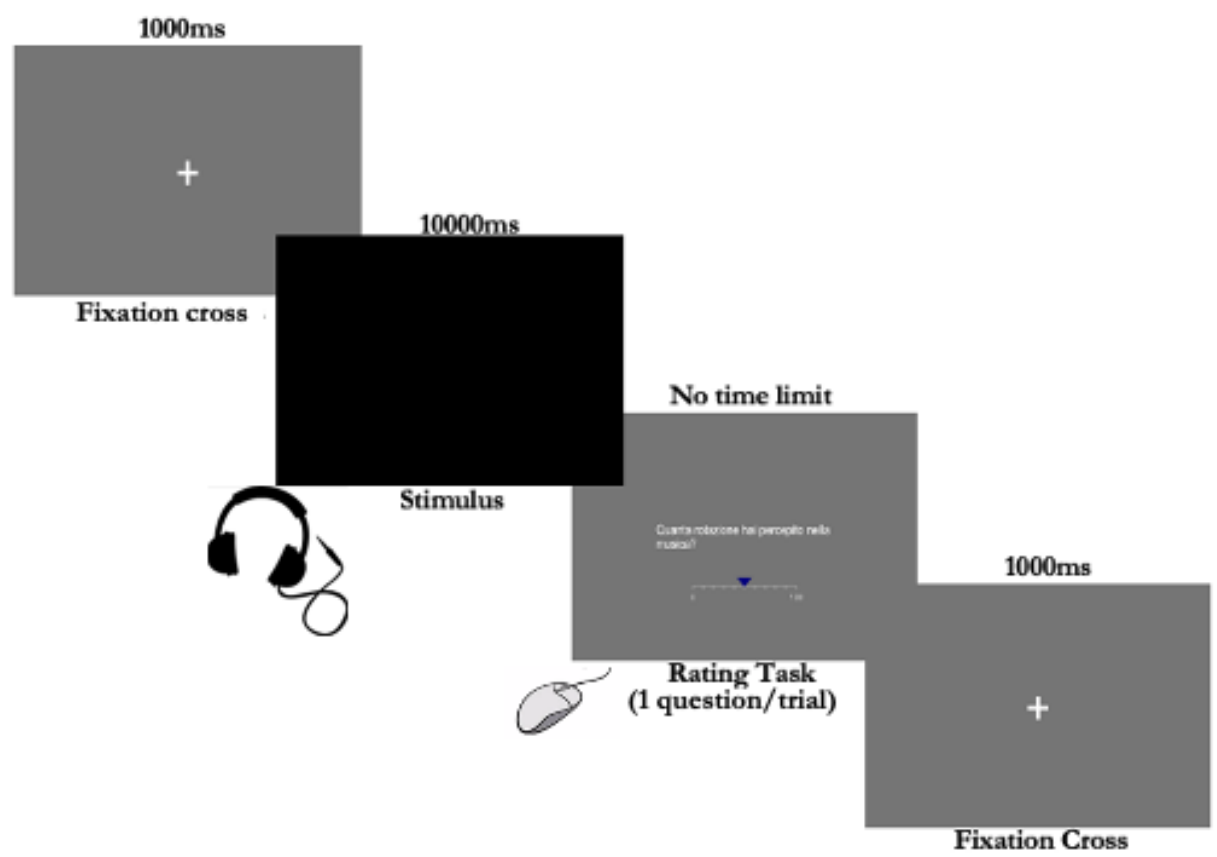

Fig. 1 | Example of experimental trial. Components: fixation cross frame (1000 ms), the stimulus frame (10000 ms) and the rating task (no time limit). Experiment was created using Psychopy 3.0.

\section{Analysis}

In order to investigate whether VAS ratings were modulated by Composition Contour (i.e., Contour), Composition Complexity (i.e., Complexity) and Note Pattern, a linear mixed effect analysis was carried out for each dependent variable. Participants' ratings were entered as dependent variables (Direction, Rotation, Movement, Emotional Involvement and Physical Involvement), Composition Contour (3 levels: Ascending, Descending, Flat), Composition Complexity (3 levels: Low, Medium, High) and Note Pattern (3 levels: Binary, Ternary and Quaternary) were entered as independent fixed variables, and participant intercepts were entered as random effects. Tukey's test was used for post-hoc comparisons among means, where an error probability of less than $5 \%(\mathrm{p}<.05)$ was considered significant in a population sample size of $\mathrm{N}=30$. All analyses were performed using R software (R Core Team, 2019) and lme4 (Bates et al. 2015), ordinal (Christensen, 2019), effects (Fox, 2003) and emmeans (Lenth, 2020) functions; for data visualization, the ggplot2 package was used (Wickham, 2016).

\section{Results}

Direction 
The model explained $55.76 \%$ of the variance in Direction ratings, taking into account the random effects $\left(\mathrm{R}^{2} \mathrm{~m}=0.53, \mathrm{R}^{2}{ }_{\mathrm{c}}=0.56\right)$. The model revealed a significant main effect of Contour $\left(\chi^{2}(2)=869.62, p<.0001\right)$, showing that participants perceived Ascending to be moving in a higher Direction with respect to Descending $\left(t_{(754)}=29.45, \mathrm{SE}=1.43, p<.0001\right.$; Ascending: $\mathrm{M}=72.10, \mathrm{SE}=1.28$; Descending: $\mathrm{M}=30.00, \mathrm{SE}=1.28)$, Ascending to be moving in a higher Direction than Flat $\left(t_{(754)}=13.33, \mathrm{SE}=1.43, p<.0001\right.$; Flat: $\left.\mathrm{M}=53.0, \mathrm{SE}=1.28\right)$, and Descending in a lower Direction than Flat $\left(t_{(754)}=-16.11, \mathrm{SE}=1.43, p<.0001\right)$, see Fig. 2A. A significant main effect for Complexity was found $\left(\chi^{2}(2)=40.76, p<.0001\right)$, showing that participants perceived High Complexity melodies to be moving in a higher direction than Medium $\left(t_{(754)}=5.99, \mathrm{SE}=1.43, p<.0001 ;\right.$ High: $\mathrm{M}=56.9, \mathrm{SE}=1.28 ;$ Medium: $\mathrm{M}=48.3$, $\mathrm{SE}=1.28)$, and High moving in a higher Direction with respect to Low $\left(t_{(754)}=4.91, \mathrm{SE}=1.43\right.$, $p<.0001$; Low: $\mathrm{M}=49.9, \mathrm{SE}=1.28$ ), see Fig. 2B. A significant main effect for Note Pattern was found $\left.\chi^{2}(2)=39.83, p<.0001\right)$, showing that participants perceived Quaternary to be moving in a higher Direction than Ternary $\left(t_{(754)}=3.31, \mathrm{SE}=1.43, p=.003\right.$; Quaternary: $\mathrm{M}=$ $56.3, \mathrm{SE}=1.28$; Ternary: $\mathrm{M}=51.6, \mathrm{SE}=1.28$ ), Binary moving in a lower Direction than Quaternary $\left(t_{(754)}=-6.31, \mathrm{SE}=1.43, p<0.0001\right.$; Binary: $\left.\mathrm{M}=47.3, \mathrm{SE}=1.28\right)$, and Binary moving in a lower Direction than Ternary $\left(t_{(754)}=-3.00, \mathrm{SE}=1.43, p=.008\right)$, see Fig. $2 \mathrm{C}$.

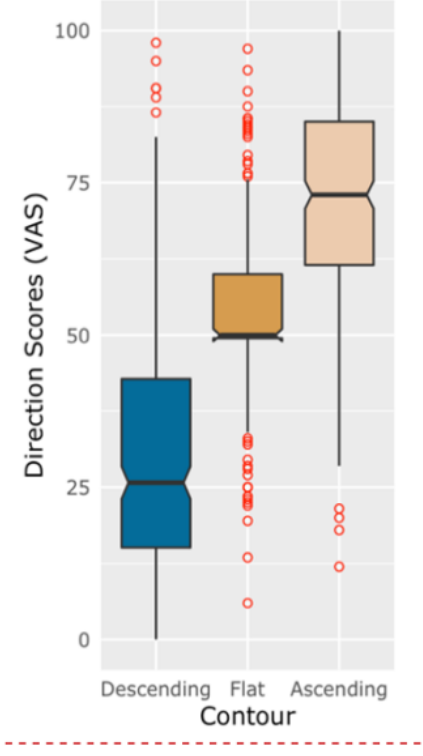

A

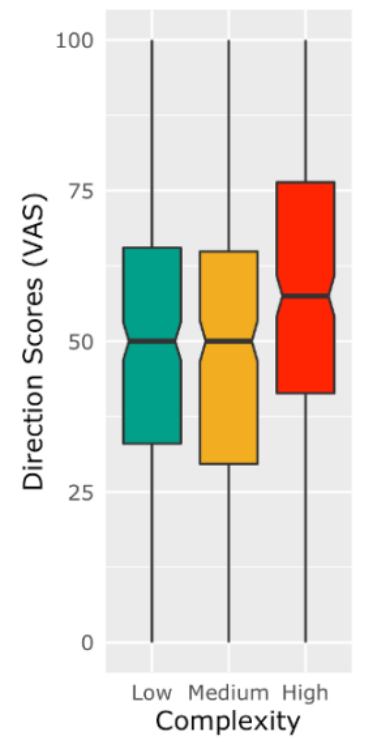

$\mathrm{B}$

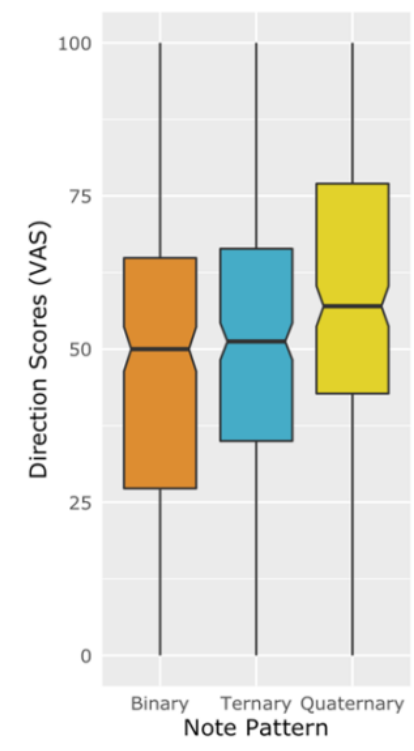

$\mathrm{C}$

Fig. 2A - C | Direction. Boxplots depicting mean Visual Analogue Scale (VAS) ratings for Direction with respect to the main effects of Composition Contour (2A), Composition Complexity (2B) and Note Pattern (2C) $(\mathrm{N}=30)$; see text for significant results. 


\section{Rotation}

The model explained $44.83 \%$ of the variance in Rotation ratings, taking into account the random effects $\left(\mathrm{R}_{\mathrm{m}}^{2}=0.29, \mathrm{R}^{2}{ }_{\mathrm{c}}=0.45\right)$. The model revealed a significant main effect of Contour $\left(\chi^{2}(2)=293.57, p<.0001\right)$, showing that participants perceived more Rotation in Ascending than in both Descending $\left(t_{(754)}=2.74, \mathrm{SE}=1.46, p=.017\right.$; Ascending: $\mathrm{M}=63.6$, $\mathrm{SE}=1.97$; Descending: $\mathrm{M}=59.6, \mathrm{SE}=1.97)$ and Flat $\left(t_{(754)}=16.02, \mathrm{SE}=1.46, p<.0001\right.$; Flat: $\mathrm{M}=40.3, \mathrm{SE}=1.97)$, and Descending more than Flat $\left(t_{(754)}=13.28, \mathrm{SE}=1.46, p<.0001\right)$, see Fig. 3A. A significant main effect for Complexity was found $\left(\chi^{2}(2)=33.83, p<.0001\right)$, showing that participants perceived more Rotation in High Complexity than Medium $\left(t_{(754)}=\right.$ 4.50, $\mathrm{SE}=1.46, p<.0001$; High: $\mathrm{M}=59.4, \mathrm{SE}=1.97$; Medium: $\mathrm{M}=52.8, \mathrm{SE}=1.97$ ), and in High with respect to Low $\left(t_{(754)}=5.44, \mathrm{SE}=1.46, p<.0001\right.$; Low: $\left.\mathrm{M}=51.4, \mathrm{SE}=1.97\right)$, see Fig. 3B. A significant main effect for Note Pattern was found $\chi^{2}(2)=54.09, p<.0001$ showing that participants perceived more Rotation in Quaternary than in Ternary $\left(t_{(754)}=2.51, \mathrm{SE}=\right.$ 1.46, $p=.033$; Quaternary: $\mathrm{M}=59.3, \mathrm{SE}=1.97$; Ternary: $\mathrm{M}=55.6, \mathrm{SE}=1.97$ ), in Binary less than Quaternary $\left(t_{(754)}=-7.24, \mathrm{SE}=1.46, p<.0001\right.$; Binary: $\left.\mathrm{M}=48.7, \mathrm{SE}=1.97\right)$, and in Binary less than in Ternary $(\mathrm{z}=-4.73, \mathrm{SE}=1.46, p<.0001)$, see Fig. 3C.

The model showed a significant Note Pattern*Contour interaction $\left(\chi^{2}(4)=12.56, p=.014\right)$, showing that participants perceived less Rotation in Binary Ascending than in Quaternary Ascending $\left(t_{(754)}=-5.56, \mathrm{SE}=2.52, p<.0001\right.$; Binary Ascending: $\mathrm{M}=56.5, \mathrm{SE}=2.45$; Quaternary Ascending: $\mathrm{M}=70.5, \mathrm{SE}=2.45$ ), less Rotation in Binary Descending than in Quaternary Descending $\left(t_{(754)}=-5.54, \mathrm{SE}=2.52, p<.0001\right.$; Binary Descending: $\mathrm{M}=52.4, \mathrm{SE}$ = 2.45; Quaternary Descending: $\mathrm{M}=66.4, \mathrm{SE}=2.45$ ), more Rotation in Binary Ascending than in Binary Flat $\left(t_{(754)}=7.62, \mathrm{SE}=2.52, p<.0001\right.$; Binary Flat: $\left.\mathrm{M}=37.3, \mathrm{SE}=2.45\right)$, more Rotation in Binary Descending than in Binary Flat $\left(t_{(754)}=5.98, \mathrm{SE}=2.52, p<.0001\right)$, more Rotation in Ternary Ascending than in Ternary Flat $\left(t_{(754)}=8.39, \mathrm{SE}=2.52, p<.0001\right)$, more Rotation in Ternary Descending than in Ternary Flat $\left(t_{(754)}=6.93, \mathrm{SE}=2.52, p<.0001\right.$; Ternary Ascending: $\mathrm{M}=63.9, \mathrm{SE}=2.45$; Ternary Flat: $\mathrm{M}=42.7$ ), more Rotation in Quaternary Ascending than in Quaternary Flat $\left(t_{(754)}=11.74, \mathrm{SE}=2.52, p<.0001\right.$; Quaternary Flat: $\mathrm{M}=$ 40.9, $\mathrm{SE}=2.45)$, and more Rotation in Quaternary Descending than in Quaternary Flat $\left(t_{(754)}=\right.$ $10.08, \mathrm{SE}=2.52, p<.0001)$. 
The model also showed a significant Complexity*Contour interaction $\left(\chi^{2}(4)=21.15, p<.001\right)$, with more Rotation in High Descending than in Low Descending $\left(t_{(754)}=3.46, \mathrm{SE}=2.52, p=\right.$ .016; High Descending: $\mathrm{M}=66.5, \mathrm{SE}=2.45$; Low Descending: $\mathrm{M}=57.7, \mathrm{SE}=2.45$ ), more Rotation in High Descending than in Medium Descending $\left(t_{(754)}=4.65, \mathrm{SE}=2.52, p<.0001\right.$; Medium Descending: $\mathrm{M}=54.7, \mathrm{SE}=2.45)$, more Rotation in High Flat than in Low Flat $\left(t_{(754)}\right.$ $=5.45, \mathrm{SE}=2.52, p<.0001$; High Flat: $\mathrm{M}=46.6, \mathrm{SE}=2.45$; Low Flat: $\mathrm{M}=32.9, \mathrm{SE}=2.45$ ), less Rotation in Low Flat than in Medium Flat $\left(t_{(754)}=-3.43, \mathrm{SE}=2.52, p=.018\right.$; Medium Flat: $\mathrm{M}=41.5, \mathrm{SE}=2.45)$, more Rotation in High Ascending than in High Flat $\left(t_{(754)}=7.31, \mathrm{SE}=\right.$ 2.52, $p$ <.0001; High Ascending: $\mathrm{M}=65.0, \mathrm{SE}=2.45)$, more Rotation in High Descending than in High Flat $\left(t_{(754)}=7.88, \mathrm{SE}=2.52, p<.0001\right)$, more Rotation in Medium Ascending than in Medium Flat $\left(t_{(754)}=8.20, \mathrm{SE}=2.52, p<.0001\right.$; Medium Ascending: $\mathrm{M}=62.2, \mathrm{SE}=$ 2.45), more Rotation in Medium Descending than in Medium Flat $\left(t_{(754)}=5.25, \mathrm{SE}=2.52, p<\right.$ $.0001)$, more Rotation in Low Ascending than in Low Flat $\left(t_{(754)}=12.24, \mathrm{SE}=2.52, p<.0001\right.$; Low Ascending: $\mathrm{M}=63.7, \mathrm{SE}=2.45$ ), and more Rotation in Low Descending than in Low Flat $\left(t_{(754)}=9.87, \mathrm{SE}=2.52, p<.0001\right)$.

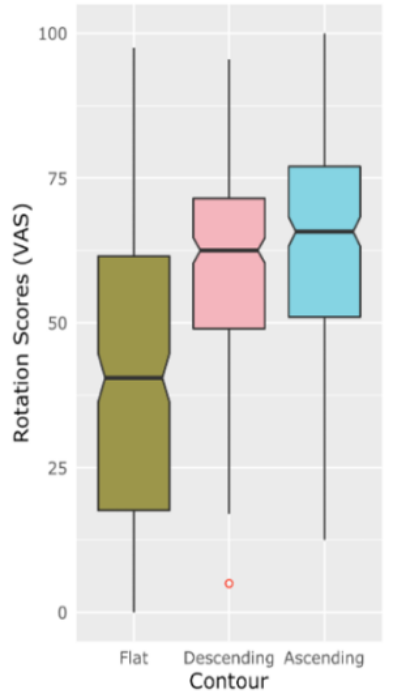

A

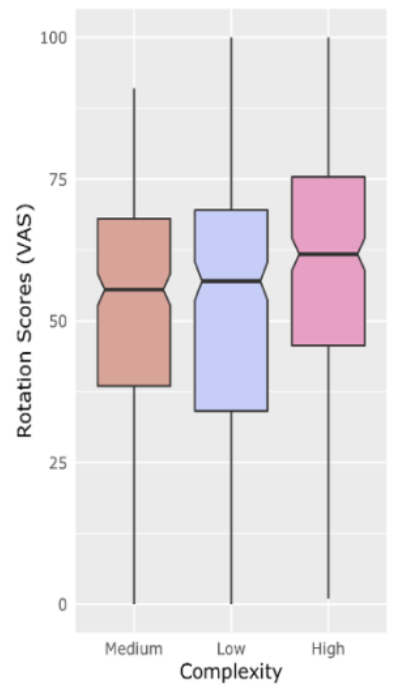

B

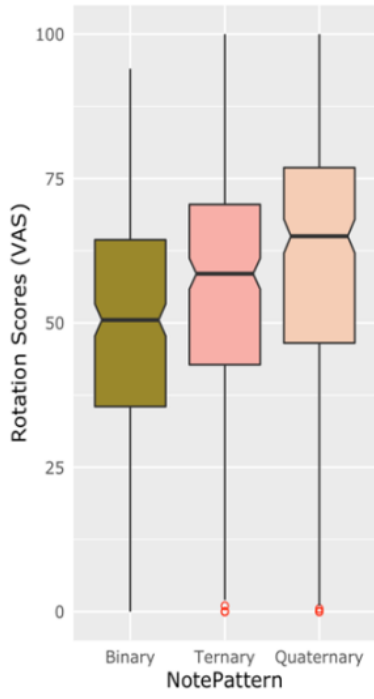

$\mathrm{C}$

Fig. 3A - C | Rotation. Boxplots depicting mean Visual Analogue Scale (VAS) ratings for Rotation with respect to main effects Composition Contour (3A), Composition Complexity (3B), and Note Pattern (3C) $(\mathrm{N}=30)$; see text for significant results.

\section{Movement}

The model explained $40.92 \%$ of the variance in Movement ratings, taking into account the random effects $\left(\mathrm{R}_{\mathrm{m}}{ }^{2}=0.27, \mathrm{R}_{\mathrm{c}}{ }_{\mathrm{c}}=0.41\right)$. The model revealed a significant main effect of 
Contour $\left(\chi^{2}(2)=141.89, p<.0001\right)$, showing that participants perceived more Movement in Ascending than in Descending $\left(t_{(754)}=3.14, \mathrm{SE}=1.3, p=0.005\right.$; Ascending: $\mathrm{M}=64.2, \mathrm{SE}=$ 1.62; Descending: $\mathrm{M}=60.1, \mathrm{SE}=1.62)$, Ascending more than Flat $(t(754)=11.52, \mathrm{SE}=1.3$, $p<.0001$; Flat: $\mathrm{M}=49.2, \mathrm{SE}=1.62)$, and Descending more than Flat $\left(t_{(754)}=8.38, \mathrm{SE}=1.3\right.$, $p<.0001)$, see Fig. 4A. A significant main effect for Complexity was found $\left(\chi^{2}(2)=55.16, p\right.$ $<.0001)$, showing that participants perceived more Movement in High than Medium $\left(t_{(754)}=\right.$ 5.46, $\mathrm{SE}=1.3, p<.0001$; High: $\mathrm{M}=63.3, \mathrm{SE}=1.62$; Medium: $\mathrm{M}=56.2, \mathrm{SE}=1.62$ ), and in High with respect to Low $\left(t_{(754)}=7.090, \mathrm{SE}=1.3, p<.0001 ;\right.$ Low: $\left.\mathrm{M}=54.1, \mathrm{SE}=1.62\right)$, see Fig. 4B. A significant main effect for Note Pattern was found $\chi^{2}(2)=136.18, p<.0001$ ), showing that participants perceived more Movement in Quaternary than in Ternary $\left(t_{(754)}=5.08, \mathrm{SE}=\right.$ 1.3, $p$ <.0001; Quaternary: $\mathrm{M}=65.1, \mathrm{SE}=1.62$; Ternary: $\mathrm{M}=58.5, \mathrm{SE}=1.62$ ), in Binary less than in Quaternary $\left(t_{(754)}=-11.638, \mathrm{SE}=1.3, p<.0001\right.$; Binary: $\left.\mathrm{M}=50.0, \mathrm{SE}=1.62\right)$, and in Binary less than in Ternary $\left(t_{(754)}=-6.560, \mathrm{SE}=1.3, p<.0001\right)$, see Fig. $4 \mathrm{C}$.

The model showed a significant Note Pattern*Complexity interaction $\left(\chi^{2}(4)=9.75, p=.045\right)$, showing that participants perceived less Movement in Binary High than in Quaternary High $\left(t_{(754)}=-5.11, \mathrm{SE}=2.25, p<.0001\right.$; Binary High: $\mathrm{M}=56.3, \mathrm{SE}=2.08$; Quaternary High: $\mathrm{M}=$ 67.8, $\mathrm{SE}=2.08)$, less Movement in Binary High than in Ternary High $\left(t_{(754)}=-4.23, \mathrm{SE}=2.25\right.$, $p<.001$; Ternary High: $\mathrm{M}=65.8, \mathrm{SE}=2.08$ ) less Movement in Binary Medium than in Quaternary Medium $\left(t_{(754)}=-6.34, \mathrm{SE}=2.25, p<.0001\right.$; Binary Medium: $\mathrm{M}=49.1, \mathrm{SE}=2.08$; Quaternary Medium: $\mathrm{M}=63.4, \mathrm{SE}=2.08$ ), more Movement in Quaternary Medium than in Ternary Medium $\left(t_{(754)}=3.28, \mathrm{SE}=2.25, p=.029\right.$; Ternary Medium: $\left.\mathrm{M}=56.0, \mathrm{SE}=2.08\right)$, less Movement in Binary Low than in Quaternary Low $\left(t_{(754)}=-8.70, \mathrm{SE}=2.25, p<.0001\right.$; Binary Low: $\mathrm{M}=44.5, \mathrm{SE}=2.08$; Quaternary Low: $\mathrm{M}=64.1, \mathrm{SE}=2.08$ ), less Movement in Binary Low than in Ternary Low $\left(t_{(754)}=-4.08, \mathrm{SE}=2.25, p=.002\right.$; Ternary Low: $\mathrm{M}=53.7$, $\mathrm{SE}=2.08)$, more Movement in Quaternary Low than in Ternary Low $\left(t_{(754)}=4.63, \mathrm{SE}=2.25\right.$, $p<.001)$, more Movement in Binary High than in Binary Low $\left(t_{(754)}=5.24, \mathrm{SE}=2.25, p<\right.$ $.0001)$, more Movement in Binary High than in Binary Medium $\left(t_{(754)}=3.17, \mathrm{SE}=2.25, p=\right.$ $.042)$, more Movement in Ternary High than in Ternary Low $\left(t_{(754)}=5.39, \mathrm{SE}=2.25, p<\right.$ $.0001)$, and more Movement in Ternary High than in Ternary Medium $\left(t_{(754)}=4.34, \mathrm{SE}=2.25\right.$, $p<.001)$, see Fig. 4D. 
The model also showed a significant Contour*Complexity interaction $\left(\chi^{2}(4)=15.37, p=.004\right)$, showing that participants perceived no significant difference in Movement between High Ascending and Low Ascending $\left(t_{(754)}=2.60, \mathrm{SE}=2.25, p=.190\right.$; High Ascending: $\mathrm{M}=68.9$, $\mathrm{SE}=2.08$; Low Ascending: $\mathrm{M}=63.1, \mathrm{SE}=2.08$ ), more Movement in High Ascending than in Medium Ascending $\left(t_{(754)}=3.73, \mathrm{SE}=2.25, p=.007\right.$; High Ascending: $\mathrm{M}=68.9, \mathrm{SE}=2.08$; Medium Ascending: $M=60.6, \mathrm{SE}=2.08$ ), more Movement in High Descending than in Low Descending $\left(t_{(754)}=5.22, \mathrm{SE}=2.25, p<.0001\right.$; High Descending: $\mathrm{M}=67.6, \mathrm{SE}=2.08$; Low Descending: $\mathrm{M}=55.9, \mathrm{SE}=2.08$ ), more Movement in High Descending than in Medium Descending $\left(t_{(754)}=4.81, \mathrm{SE}=2.25, p<.0001\right.$; Medium Descending: $\left.\mathrm{M}=56.8, \mathrm{SE}=2.08\right)$, more Movement in High Flat than in Low Flat $\left(t_{(754)}=4.47, \mathrm{SE}=2.25, p<.001\right.$; High Flat: $\mathrm{M}$ $=53.3, \mathrm{SE}=2.08$; Low Flat: $\mathrm{M}=43.2, \mathrm{SE}=2.08$ ), less Movement in Low Flat than in Medium Flat $\left(t_{(754)}=-3.54, \mathrm{SE}=2.25, p=.012\right.$; Medium Flat: $\left.\mathrm{M}=51.2, \mathrm{SE}=2.08\right)$, more Movement in High Ascending than in High Flat $\left(t_{(754)}=6.96, \mathrm{SE}=2.25, p<.0001\right)$, more Movement in High Descending than in High Flat $\left(t_{(754)}=6.39, \mathrm{SE}=2.25, p<.0001\right)$, more Movement in Medium Ascending than in Medium Flat $\left(t_{(754)}=4.16, \mathrm{SE}=2.25, p=.001\right)$, more Movement in Low Ascending than in Low Flat $\left(t_{(754)}=8.83\right.$, $\mathrm{SE}=2.25, p<.0001$; Low Ascending: $\mathrm{M}=$ 63.1, $\mathrm{SE}=2.08)$, more Movement in Low Descending than in Low Flat $\left(t_{(754)}=5.63\right.$, $\mathrm{SE}=$ $2.25, p<.0001)$, and more Movement in Low Ascending than in Low Descending $\left(t_{(754)}=3.20\right.$, $\mathrm{SE}=2.25, p=.038)$. 


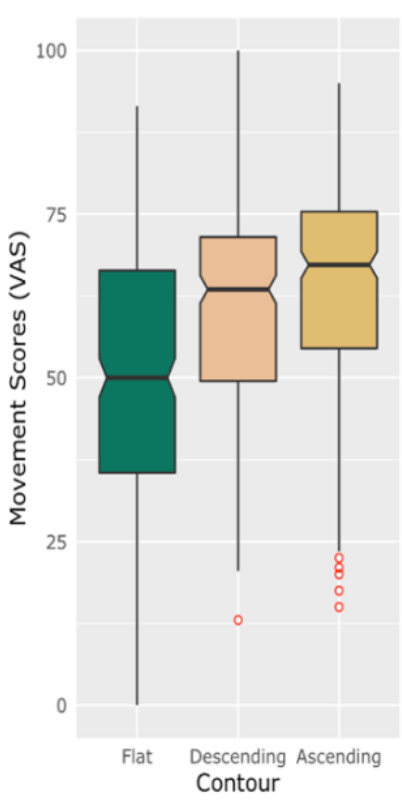

A

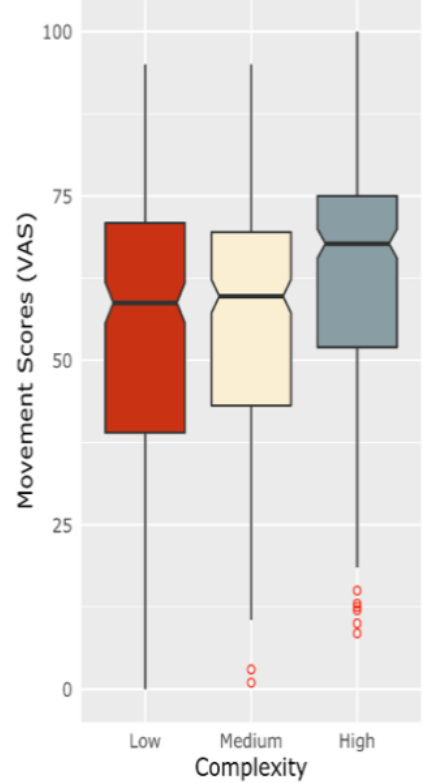

B

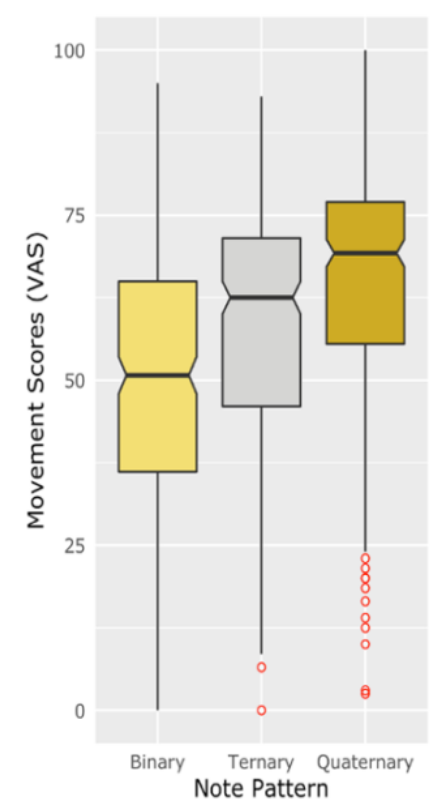

$\mathrm{C}$

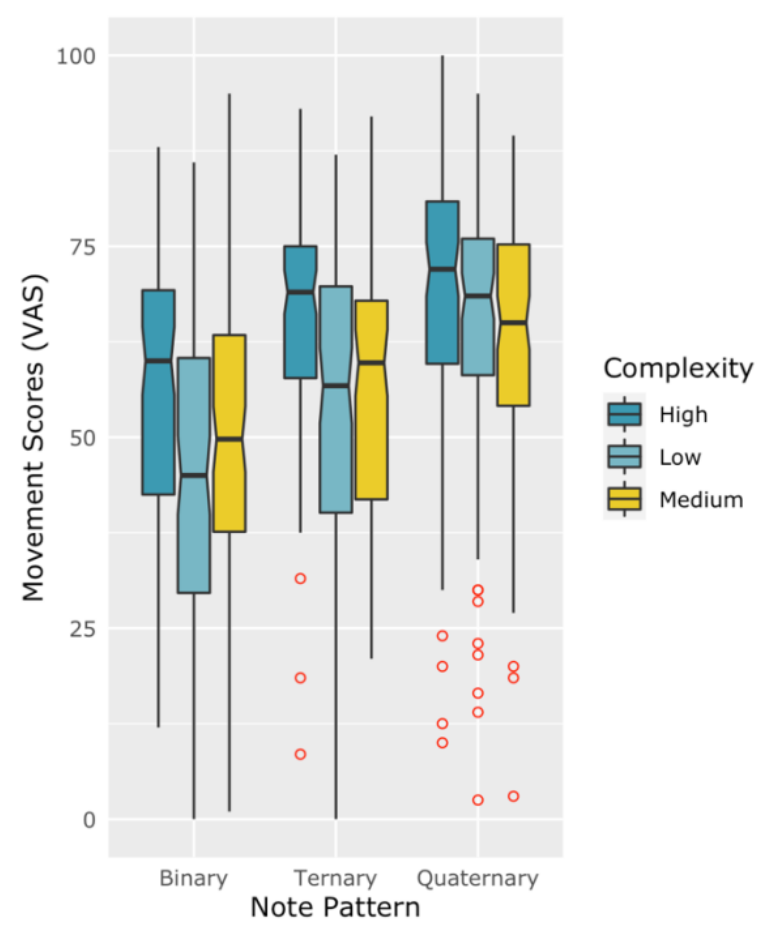

$\mathrm{D}$

Fig. 4A - D | Movement. Boxplots depicting mean Visual Analogue Scale (VAS) ratings for Movement with respect to main effects Composition Contour (4A), Composition Complexity (4B), and Note Pattern (4C), and a Note Pattern*Complexity interaction effect (4D) $(\mathrm{N}=30)$; see text for significant results. 


\section{Physical Involvement}

The model explained $42.01 \%$ of the variance in Physical Involvement ratings, taking into account the random effects $\left(\mathrm{R}_{\mathrm{m}}^{2}=0.12, \mathrm{R}^{2} \mathrm{c}=0.42\right)$. The model revealed a significant main effect of Contour $\left(\chi_{(2)}^{2}=61.05, p<.0001\right)$, showing that participants felt more Physically Involved in Ascending than with Descending $\left(t_{(754)}=2.46, \mathrm{SE}=1.31, p=.037\right.$; Ascending: $\mathrm{M}$ $=51.3, \mathrm{SE}=2.21$; Descending: $\mathrm{M}=48.1, \mathrm{SE}=2.21)$, Ascending more than with Flat $\left(t_{(754)}=\right.$ 7.65, $\mathrm{SE}=1.31, p<.0001$; Flat: $\mathrm{M}=41.3, \mathrm{SE}=2.21$ ), and Descending more than with Flat $\left(t_{(754)}=5.19, \mathrm{SE}=1.31, p<.0001\right)$, see Fig. 5A. A significant main effect for Complexity was found $\left(\chi^{2}(2)=30.93, p<.0001\right)$, showing that participants felt more Physically Involved with High than with Medium $\left(t_{(754)}=3.03, \mathrm{SE}=1.31, p=.007\right.$; High: $\mathrm{M}=50.6, \mathrm{SE}=2.21$; Medium: $\mathrm{M}=46.7, \mathrm{SE}=2.21)$, with High more than with Low $\left(t_{(754)}=5.55, \mathrm{SE}=1.31, p<.0001\right.$; Low: $\mathrm{M}=43.4, \mathrm{SE}=2.21)$, and with Low less than with Medium $\left(t_{(754)}=-2.52, \mathrm{SE}=1.31, p=.032\right)$, see Fig. 5B. A significant main effect for Note Pattern was found $\chi^{2}(2)=41.22, p<.0001$ ), showing that participants felt more Physically Involved with Quaternary than with Ternary $\left(t_{(754)}=2.87, \mathrm{SE}=1.31, p=.012\right.$; Quaternary: $\mathrm{M}=50.9, \mathrm{SE}=1.31$; Ternary: $\mathrm{M}=47.2, \mathrm{SE}=$ $2.21)$, with Binary less than with Quaternary $\left(t_{(754)}=-6.41, \mathrm{SE}=1.31, p<.0001 ;\right.$ Binary: $\mathrm{M}=$ 42.5, $\mathrm{SE}=2.21)$, and with Binary less than with Ternary $(t(754)=-3.54, \mathrm{SE}=1.31, p=.001)$, see Fig. 5C.

The model also showed a significant Complexity*Contour interaction $\left(\chi^{2}(4)=9.77, p=0.045\right)$, showing that participants perceived more Physical Involvement in High Descending than in Medium Descending $\left(t_{(754)}=3.52, \mathrm{SE}=2.27, p=.013\right.$; High Descending: $\mathrm{M}=52.8, \mathrm{SE}=2.57$; Medium Descending: $\mathrm{M}=44.8, \mathrm{SE}=2.57$ ), more Physical Involvement in High Flat than in Low Flat $\left(t_{(754)}=4.25, \mathrm{SE}=2.27, p<.001\right.$; High Flat: $\mathrm{M}=45.6, \mathrm{SE}=2.57$; Low Flat: $\mathrm{M}=$ $35.9, \mathrm{SE}=2.57)$, more Physical Involvement in High Ascending than in High Flat $\left(t_{(754)}=3.51\right.$, $\mathrm{SE}=2.27, p=.014$; High Ascending: $\mathrm{M}=53.5, \mathrm{SE}=2.57$ ), more Physical Involvement in High Descending than in High Flat $\left(t_{(754)}=3.20, \mathrm{SE}=2.27, p=.040\right)$, more Physical Involvement in Medium Ascending than in Medium Flat $\left(t_{(754)}=4.62, \mathrm{SE}=2.27, p<.001\right.$; Medium Ascending: $\mathrm{M}=52.8, \mathrm{SE}=2.57$; Medium Flat: $\mathrm{M}=42.4, \mathrm{SE}=2.57$ ), more Physical Involvement in Medium Ascending than in Medium Descending $\left(t_{(754)}=3.53, \mathrm{SE}=2.27, p=\right.$ .013), more Physical Involvement in Low Ascending than in Low Flat $\left(t_{(754)}=5.12, \mathrm{SE}=2.27\right.$, $p<.0001$; Low Ascending: $\mathrm{M}=47.5, \mathrm{SE}=2.57$ ), more Physical Involvement in Low 
Descending than in Low Flat $\left(t_{(754)}=4.71, \mathrm{SE}=2.27, p<.0001\right.$; Low Descending: $\mathrm{M}=46.6$, $\mathrm{SE}=2.57)$.

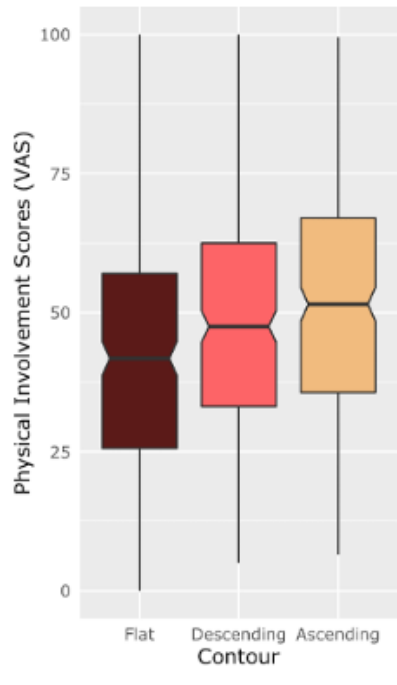

A

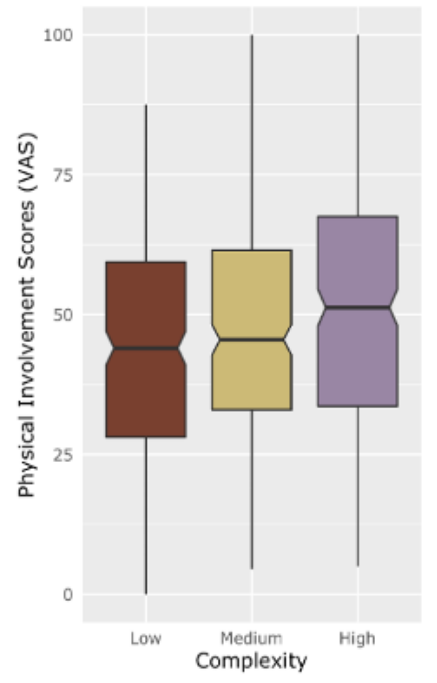

B

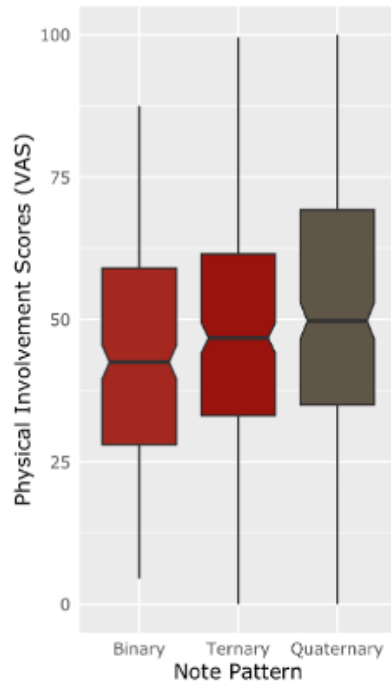

$\mathrm{C}$

Fig. 5A - C | Physical Involvement. Boxplots depicting mean Visual Analogue Scale (VAS) ratings for Physical Involvement with respect to main effects Composition Contour (5A), Composition Complexity (5B), and Note Pattern (5C) $(\mathrm{N}=30)$; see text for significant results.

\section{Emotional Involvement}

The model explained $53.45 \%$ of the variance in Emotional Involvement ratings, taking into account the random effects $\left(\mathrm{R}_{\mathrm{m}}{ }^{2}=0.11, \mathrm{R}_{\mathrm{c}}{ }_{\mathrm{c}}=0.53\right)$. The model revealed a significant main effect of Contour $\left(\chi^{2}(2)=120.95, p<.0001\right)$, showing that participants felt more Emotionally Involved with Ascending than with Descending $\left(t_{(754)}=3.16, \mathrm{SE}=1.27, p=.005\right.$; Ascending: $\mathrm{M}=52.6, \mathrm{SE}=2.73$; Descending: $\mathrm{M}=48.6, \mathrm{SE}=2.73$ ), more Emotionally Involved with Ascending than with Flat $\left(t_{(754)}=10.70, \mathrm{SE}=1.27, p<.0001\right.$; Flat: $\left.\mathrm{M}=39.0, \mathrm{SE}=2.73\right)$, and with Descending more than with Flat $\left(t_{(754)}=7.55, \mathrm{SE}=1.27, p<.0001\right)$, see Fig. 6A. A significant main effect for Complexity was found $\left(\chi_{(2)}^{2}=22.35, p<.0001\right)$, showing that participants felt more Emotionally Involved with High Complexity than with Low $\left(t_{(754)}=4.64\right.$, $\mathrm{SE}=1.27, p<.0001$; High: $\mathrm{M}=49.4, \mathrm{SE}=2.73$ Low: $\mathrm{M}=43.5, \mathrm{SE}=2.73$ ), and with Low less than with Medium $\left(t_{(754)}=-3.12, \mathrm{SE}=1.27, p=.005\right.$; Medium: $\left.\mathrm{M}=47.4, \mathrm{SE}=2.73\right)$, see Fig. 6B.. A significant main effect for Note Pattern was found $\chi^{2}(2)=21.30, p<.0001$ ), showing that participants felt less Emotionally Involved with Binary than with Quaternary $\left(t_{(754)}=-4.55\right.$, $\mathrm{SE}=1.27, p<.0001$; Quaternary: $\mathrm{M}=49.4, \mathrm{SE}=2.73$; Binary: $\mathrm{M}=43.6, \mathrm{SE}=2.73$ ), and less 
with Binary than with Ternary $\left(t_{(754)}=-2.93, \mathrm{SE}=1.27, p=.01\right.$; Ternary: $\left.\mathrm{M}=47.3, \mathrm{SE}=2.73\right)$, see Fig. 6C.

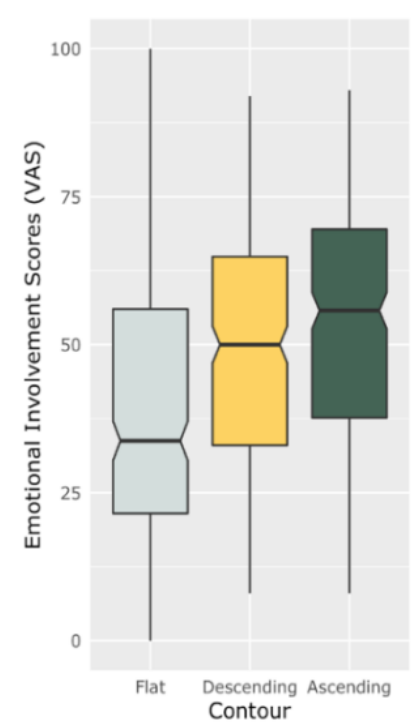

A

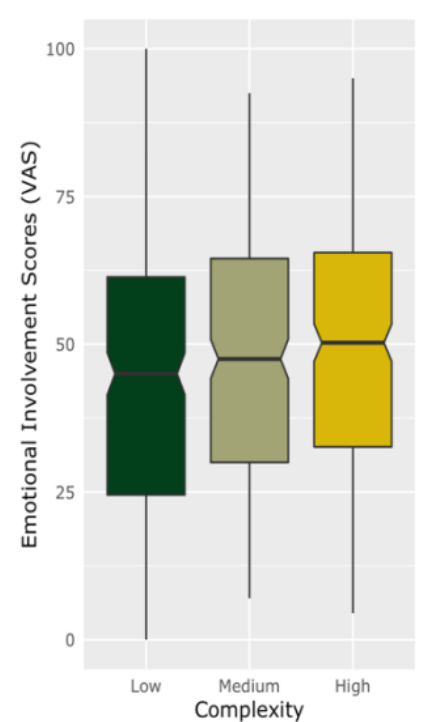

B

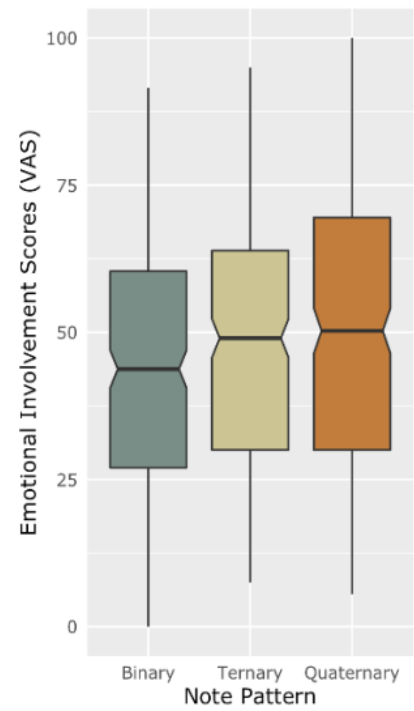

$\mathrm{C}$

Fig. 6A - C | Emotional Involvement. Boxplots depicting mean Visual Analogue Scale (VAS) ratings for Emotional Involvement with respect to main effects Composition Contour (6A), Composition Complexity (6B), and Note Pattern (6C) $(\mathrm{N}=30)$; see text for significant results.

\section{Discussion}

In the present study, we investigated the impact of Contour (Ascending, Descending, Flat), Complexity (Low, Medium, High) and Note Pattern (Binary, Ternary, Quaternary) on participant ratings of Direction, perceived Movement, perceived Rotation, Physical Involvement, and Emotional Involvement in nonmusicians. In order to extend the ecological validity of the study, we collaborated with composer Eduardo Andrade to create 27 novel and carefully controlled musical stimuli recorded on a digital piano. The experimental task was to rate the stimuli using a Visual Analogue Scale (VAS) ranging from 0 to 100.

Firstly, for the dependent variable Direction, results demonstrate significant main effects for Contour, Complexity and Note Pattern. It was demonstrated that, in line with our hypothesis, Ascending conditions were perceived as moving upward, Descending conditions were perceived as moving downward, and Flat conditions were perceived as moving neither upward nor downward. This result confirms that participants were able to identify the Contour of the melodies; however, it is not possible to conclude whether participants felt the direction of the 
Composition Contour on a bodily level, or whether they judged the direction of the melody based on the last set of few high or low notes, which are easier to discern. Furthermore, the present study only measured perceived vertical direction. While verticality is a common means of expressing pitch direction in Western languages, other languages may use different metaphors to describe pitch space, which could influence perception (e.g., size metaphors for pitch in Croatian; Žuvela \& Anić, 2019). More studies are needed to confirm this result. Results also show that High Complexity was perceived to be moving in a higher Direction than Medium and Low, suggesting that the higher melodic line in High Complexity tracks enhances the perception of upward movement.

For dependent variable Rotation, results demonstrate significant main effects for Composition Contour, Composition Complexity and Note Pattern. Specifically, it was demonstrated that participants perceive more Rotation in melodies with Ascending Contour than those with Descending Contour, and that they perceive more Rotation in Ascending and Descending than in Flat melodies, in line with Hansen and Huron's (2019) result that the sensation of rotation is perceived in loudness/accent patterns consistent with rotating trajectories in pitch that is moving. Notably, in line with our hypothesis and Hansen and Huron's findings, it was demonstrated that Quaternary and Ternary Note Patterns were perceived as evoking significantly more Rotation than Binary conditions. However, results also show that Quaternary evokes significantly more Rotation than Ternary, contrary to our hypothesis and Hansen and Huron's findings. Quaternary melodies have higher note density (4 beats per measure, compared to 2 -such as in Binary, or 3 -such as in Ternary), and as all stimuli have a duration of 10 seconds, Quaternary melodies also have the fastest tempo. Future studies are needed to determine whether this result may be due to a lack of a control for the melodies' accent structures, and thus participants' confounding of rotation with tempo, as demonstrated in Hansen and Huron's findings that perceived rotation increases with tempo. In addition, significant Complexity*Contour and Note Pattern*Contour interactions suggest that low ratings for Flat Contour amplify the significant main effect that Ascending is perceived as evoking a greater sense of Rotation than Descending (this effect is also evident in the Contour interaction effects for Movement and Physical Involvement).

Results for the Movement measure show significant main effects of Composition Contour, Composition Complexity and Note Pattern. Specifically, it was found that, even though the 
tempo, interval size and note density were equivalent in all conditions, participants not only perceived more Movement in Ascending and Descending conditions with respect to Flat, but more Movement in Ascending than in Descending conditions. These results provide preliminary evidence for the hypothesis that Contour modulates perceived Movement in participants. Importantly, it was also shown that that High Complexity melodies are perceived as evoking greater perceived Movement than Medium and Low, and Medium more so than Low. These results suggest that participants may associate greater note density with a greater amount of gestures needed to produce the notes, and thus that notes are indeed perceived as kinetic events, in line with the theory of musical mimetic participation of the embodied music cognition framework (Cox, 2017). Our results also demonstrate that Quaternary is perceived as evoking greater Movement than Ternary and Binary, and Ternary more than Binary, indicating again that note density and/or tempo modulate participants' perception of Movement. However, a significant Complexity*Note Pattern interaction indicates that there is a threshold effect for the perception of Movement in Quaternary melodies of different Complexity (i..e, no significant differences between Quaternary Low, Quaternary Medium and Quaternary High).

For the dependent variable Physical Involvement, results demonstrate significant main effects for Composition Contour, Composition Complexity and Note Pattern. Specifically, Ascending melodies are perceived as more Physically Involving than both Descending and Flat, and Descending more than Flat. This follows the same pattern of results as for perceived Movement, showing that participants associate Ascending Contour with greater exertion or effort, in line with "greater [exertion] is higher" hypothesis of the embodied music cognition framework (Cox, 2017). In addition to the greater effort perceived in the high, harder-to-reach notes of Ascending melodies, participants may also associate Ascending piano melodies with the felt vibration of sung high notes in the head region (for high notes), as opposed to chest voice (for lower notes). Results also demonstrate that participants perceive High Complexity melodies to be more Physically Involving than Low and Medium Complexity, and Medium more than Low, providing further support for the mimetic participation theory (Cox 2017). Results also indicate that Quaternary Note Pattern is perceived as more Physically Involving than Ternary and Binary, and Ternary more than Binary, providing further evidence in support of the modulating effect of note density on Physical Involvement. 
Finally, for Emotional Involvement, results demonstrate significant main effects for Composition Contour, Composition Complexity and Note Pattern. Participants perceive melodies with Ascending Contour to be more Emotionally Involving than both Flat and Descending melodies, and Descending more so than Flat. This result suggests that the stronger musical affect evoked by Ascending melodies may be driven by greater perceived exertion and thus mimetic participation, providing preliminary support for the mimetic subvocalization and voice as source domain hypotheses (Cox, 2017). When listening to "Nessun dorma" from Puccini's "Turandot", for example, one cannot help but mimic what it would be like to perform the "physical-artistic accomplishment" of sustaining the high B of the final "Vincerò!" (Cox, 2017: 91). As the goal-oriented nature of music is often structured on climactic moments composed of melodic high points (Eitan, 1997), and these highpoints often correlate with greater pitch height and greater acoustic strength (i.e., volume), the sense of "achievement" and emotional high-point in music is amplified. However, the volume across all stimuli was kept constant, suggesting that Ascending Contour is perceived as more Emotionally Involving than Descending Contour irrespective of acoustic strength. Results also demonstrate that High Complexity is more Emotionally Involving than Low, and Medium more so than Low, suggesting that note density may modulate Emotional Involvement, but the difference in note density between High and Medium Complexity is not salient enough for such a modulation. The results for Note Pattern, with Quaternary perceived as being more Emotionally Involving than Binary, and Ternary more than Binary, may indicate a similar modulating effect of note density.

Altogether, these results support the embodied music cognition framework (Godøy and Leman, 2010; Cox, 2017) and the voice as source domain and mimetic subvocalization hypotheses (Cox, 2017), in particular. They also provide strong empirical evidence for enduring notions of melodic motion (e.g., Hanslick, 1891; Schenker, 1854; Truslit, 1938; Pratt, 1931; Sessions, 1941; Zuckerkandl, 1956), and moderate support for the Ecological Theory of Rotating Sounds (Hansen and Huron 2019). Future studies are needed to further investigate the perception of rotation in melodies with different note patterns controlled for note density (i.e., modified accent structures), as well as the impact of the musical gestures of contour and rotation on cortical sensorimotor activation in the brain. 


\section{References}

Bates, D., Mächler, M., Bolker, B. and Walker, S. (2014) 'Fitting linear mixed-effects models using lme4', arXiv preprint arXiv:1406.5823.

Baumann, S., Koeneke, S., Schmidt, C. F., Meyer, M., Lutz, K. and Jancke, L. (2007) 'A network for audio-motor coordination in skilled pianists and non-musicians', Brain Research, 1161, pp. 65-78. doi: 10.1016/j.brainres.2007.05.045.

Callan, D. E., Tsytsarev, V., Hanakawa, T., Callan, A. M., Katsuhara, M., Fukuyama, H. and Turner, R. (2006) 'Song and speech: brain regions involved with perception and covert production', Neuroimage. Elsevier, 31(3), pp. 1327-1342.

Chen, J. L., Penhune, V. B. and Zatorre, R. J. (2008a) 'Listening to musical rhythms recruits motor regions of the brain', Cerebral cortex. Oxford University Press, 18(12), pp. 2844-2854.

Chen, J. L., Penhune, V. B. and Zatorre, R. J. (2008b) 'Moving on time: brain network for auditory-motor synchronization is modulated by rhythm complexity and musical training', Journal of cognitive neuroscience. MIT Press, 20(2), pp. 226-239.

Christensen, R. H. B. (2019) 'A Tutorial on fitting Cumulative Link Mixed Models with clmm2 from the ordinal Package', Tutorial for the $R$ Package ordinal https://cran. $r$-project. org/web/packages/ordinal/Accessed, 1.

Core, T. R. (2019) R: A language and environment for statistical computing. Vienna, Austria.

Cox, A. (2001) 'The mimetic hypothesis and embodied musical meaning', Musicae scientiae. SAGE Publications Sage UK: London, England, 5(2), pp. 195-212.

Cox, A. (2011) 'Embodying music: Principles of the mimetic hypothesis', Music Theory Online, 17(2).

Cox, A. (2017) Music and Embodied Cognition: Listening, Moving, Feeling, and Thinking. Illustrated edition. Bloomington; Indianapolis: Indiana University Press.

Davis, M. H. (1980) 'A multidimensional approach to individual differences in empathy'. American Psychological Association Washington, DC.

Faul, F., Erdfelder, E., Lang, A.-G. and Buchner, A. (2007) 'G* Power 3: A flexible statistical power analysis program for the social, behavioral, and biomedical sciences', Behavior research methods. Springer, 39(2), pp. 175-191.

Fox, J. (2003) 'Effect displays in R for generalised linear models', Journal of statistical software, 8(15), pp. 1-27.

Gibson, J. J. (1966) 'The senses considered as perceptual systems.' Houghton Mifflin.

Gibson, J. J. (1979) The ecological approach to visual perception. Boston, MA, US. Houghton, Mifflin and Company. 
Godøy, R. I. and Leman, M. (eds) (2010) Musical Gestures: Sound, Movement, and Meaning. 1st edition. New York: Routledge.

Goswami, U. (2015) 'Sensory theories of developmental dyslexia: three challenges for research', Nature Reviews Neuroscience. Nature Publishing Group, 16(1), pp. 43-54.

Halpern, A. R. and Zatorre, R. J. (1999) 'When that tune runs through your head: a PET investigation of auditory imagery for familiar melodies', Cerebral cortex. Oxford University Press, 9(7), pp. 697-704.

Halpern, A. R., Zatorre, R. J., Bouffard, M. and Johnson, J. A. (2004) 'Behavioral and neural correlates of perceived and imagined musical timbre', Neuropsychologia. Elsevier, 42(9), pp. $1281-1292$.

Hansen, N. C. and Huron, D. (2019) 'Twirling triplets: the qualia of rotation and musical rhythm', Music \& Science. SAGE Publications Sage UK: London, England, 2, p. 2059204318812243.

Hanslick, E. (1891) The beautiful in music: a contribution to the revisal of musical aesthetics. Novello.

Hickok, G., Buchsbaum, B., Humphries, C. and Muftuler, T. (2003) 'Auditory-motor interaction revealed by fMRI: speech, music, and working memory in area Spt', Journal of cognitive neuroscience. MIT Press, 15(5), pp. 673-682.

Kelkar, T., \& Jensenius, A. R. (2019). 'Exploring melody and motion features in "soundtracings", Proceedings of the 14th Sound and Music Computing Conference 2017, SMC 2017, 98-103.

Koelsch, S. (2012) Brain and Music. John Wiley \& Sons.

Langer, S. K. (1957) Problems of Art. Charles Scribner's Sons.

Molnar-Szakacs, I. and Overy, K. (2006). 'Music and mirror neurons: from motion to'e'motion', Social cognitive and affective neuroscience, 1(3), pp. 235-241.

Ndebele, P. (2013) 'The Declaration of Helsinki, 50 years later', Jama. American Medical Association, 310(20), pp. 2145-2146.

Oldfield, R. C. (1971) 'The assessment and analysis of handedness: the Edinburgh inventory', Neuropsychologia. Oxford, 9(1), pp. 97-113.

Overy, K. (2003) 'Dyslexia and music: From timing deficits to musical intervention', Annals of the New York Academy of Sciences. Blackwell Publishing Ltd Oxford, UK, 999(1), pp. 497505.

Overy, K., \& Molnar-Szakacs, I. (2009). 'Being together in time: Musical experience and the mirror neuron system', Music perception, 26(5), pp. 489-504. 
Patel, A. D. (2009) 'Snowball the Dancing Cockatoo'. IUPUI (Campus). Office of Communications and Marketing.

Peirce, J., Gray, J., Simpson, S., MacAskill, M., Höchenberger, R., Sogo, H., Kastman, E., Lindeløv J. (2019) 'PsychoPy2: experiments in behavior made easy. Behavior Research Methods. 10.3758/s13428-018-01193-y.

Pratt, C. C. (1931) The Meaning of Music - A Study in Psychological Aesthetics. Johnson Reprint Corporation.

Repp, B. (1992) 'Music as Motion: A Synopsis of Alexander Truslit's (1938)', Haskins Laboratories Status Report on Speech Research, pp. 265-278.

Roberts, R., Callow, N., Hardy, L., Markland, D. and Bringer, J. (2008) 'Movement imagery ability: development and assessment of a revised version of the vividness of movement imagery questionnaire', Journal of Sport and Exercise Psychology. Human Kinetics, Inc., 30(2), pp. 200-221.

Rouse, A. A., Cook, P. F., Large, E. W. and Reichmuth, C. (2016) 'Beat keeping in a sea lion as coupled oscillation: implications for comparative understanding of human rhythm', Frontiers in neuroscience. Frontiers, 10, p. 257.

Schenker, H. (1954) Harmony. University of Chicago Press.

Sessions, R. (1941) The Composer and His Message In: The Intent of the Artist. Edited by A. Centeno. Princeton: Princeton University Press.

Sparks, R., Helm, N. and Albert, M. (1974) 'Aphasia rehabilitation resulting from melodic intonation therapy', Cortex. Elsevier, 10(4), pp. 303-316.

Stern, D. N. (2010) Forms of Vitality: Exploring Dynamic Experience in Psychology and the Arts. Illustrated edition. Oxford; New York: Oxford University Press.

Walker, M. E. (2000) 'Movement and Metaphor: Towards an Embodied Theory of Music Cognition and Hermeneutics', p. 16.

Werner, P. D., Swope, A. J. and Heide, F. J. (2006) 'The music experience questionnaire: Development and correlates', The Journal of Psychology. Taylor \& Francis, 140(4), pp. 329345.

Wickham, H. (2016) ggplot2: Elegant graphics for data analysis. Springer.

Witmer, B. G. and Singer, M. J. (1998) 'Measuring presence in virtual environments: A presence questionnaire', Presence. MIT Press, 7(3), pp. 225-240.

Wolff, P. H. (2002) 'Timing precision and rhythm in developmental dyslexia', Reading and Writing. Springer, 15(1-2), pp. 179-206. 
Zatorre, R. J., Halpern, A. R., Perry, D. W., Meyer, E. and Evans, A. C. (1996) 'Hearing in the mind's ear: a PET investigation of musical imagery and perception', Journal of cognitive neuroscience. MIT Press, 8(1), pp. 29-46.

Zbikowski, L. M. (2002) Conceptualizing music: Cognitive structure, theory, and analysis. Oxford University Press on Demand.

Zuckerkandl, V. (1956) Sound and Symbol: Music and the External World. Pantheon.

Žuvela, S. K. and Anić, A. O. (2019) 'The embodied and the cultural in the conceptualization of pitch space in Croatian', Jezikoslovlje, 20(2). 199-219. 


\section{Conflicts of Interest}

The authors declare that the research was conducted in the absence of any commercial or financial relationships that could be construed as a potential conflict of interest.

\section{Author Contributions}

Conceived of the experiment: AK, JB, EA; designed the experiment: AK, JB, EA, MM, MC, MM, MAU; performed the experiment: AK, MM, MP; analyzed the data: AK, NL; wrote the initial draft: AK; initiated the project: AK, MC, MAU, VG, MG. All authors contributed substantially to the revision of the initial draft and approval of the final version of the manuscript.

\section{Funding}

For this research, AK received funding from the Cariparma Foundation.

\section{Acknowledgements}

The authors would like to thank Gioacchino Garofalo and Francesca Siri for their help with the research design and creation of the Python script. 